that strictly speaking this would be more correct, but we fear that the conventional use of the terms by ophthalmologists is of too long standing to be altered for theoretical reasons.

We must congratulate the author on the necessity for a second edition so soon after the first, as this must indicate that the book has been found to supply a want.

\title{
CORRESPONDENCE
}

\section{MINERS' NYSTAGMUS}

To the Editor of The British Journal of Ophthalmology

SIR,-I am inclined to agree with $\mathrm{Mr}$. A. S. Percival of Newcastle-on-Tyne that in a certain percentage of cases there is a predisposition to the disease from childhood. I am also of opinion that a condition may arise in the eye in later life which tends to induce the condition.

Appended are notes of two cases sent to me for examination on July 20, 1921, which may prove of interest.

1. Richard C., 55, coal miner, residing at Tyne Dock, County Durham. At work last on October 19, 1917. Complains of blindness, giddiness, pains in the eyes, the forehead, and back of head. Has good health otherwise. Eats well and sleeps well. Smokes two ounces of twist tobacco per week. Does not chew tobacco. Does not read. Can read a certain amount with glasses, but does not do so because of fatigue. Has slight nystagmus. Fundi healthy. Commencing cataract. Some central opacity in each lens, more dense in right one. Is hypermetropic.

R.V. 6/60 with $+2 \mathrm{D}$ sph. $6 / 36$.

L.V. $6 / 64$ with $+2 \mathrm{D}$ sph. $6 / 12$.

In this case the nystagmus was distinctly slight. I think he probably had changes coming on slowly in his lenses for a long period. Of course, he was unfit to go to work in a mine again.

2. Thomas Y., 44, miner, Tyne Dock, County Durham. At work last in October, 1914. Complained at that time that "everything was going round and round," also dizziness. When got down the pit had to sit down for a quarter of an hour before able to see the road he had to take. Was very bad on coming out of the mine. He started work in a mine when 13 years of age, and was there until 20. After that was away from mining for 14 years. and worked at filling grain and iron ore. After this he worked in a coal mine for about four years and then developed nystagmus. 
He says he is a healthy man. Eats well and sleeps well. Smokes two ounces of twist tobacco per week. Does not chew tobacco.

Right Eye. He states has been defective since he was eighteen months old. Examination of the eye shows that he has had an ulcer of the cornea with perforation, there being an adherent leucoma present. Pupil inclines to pear shape, and is elongated. Right Vision-Can only see hand movements close to the face.

Left Eye. Pupil pear-shaped and elongated with nartow end downwards. I take it due probably to partial coloboma of the iris. Well marked nystagmus. What looks like remains of pupillary membrane in the pupil. Fundus looks healthy.

L.V. $=6 / 60$ with $-2 \mathrm{D}$ Sph. $\leftrightharpoons-1 \mathrm{D}$ cyl. axis $150^{\circ} 6 / 12$.

This man, comparatively young, was of course quite unfit to go down a mine and always would be. I believe this man when a child had some nystagmus. At any rate he would have a marked predisposition to it because of the congenital anomaly in each eye. As I said at the time this man should never have been allowed down a mine. It was the worst possible thing for him. A case like this points to the necessity, in the interests of both employers and employees, of having the eyes of boys and men examined before they take up the occupation of working in a coal mine.

\section{Your faithfully,}

\section{G. Victor Miller.}

STOCKTON-ON-TEES,

June 2, 1924.

\section{FUTURE ARRANGEMENTS}

September 1-6.-Course on the slit-lamp at the Ophthalmic Clinic of Zürich.

In answer to a number of applicants who could not be accommodated last year, Professor Vogt will hold a course in slit-lamp work, combined with demonstrations of the fundus in red-free light, from September 1 to 6, inclusive, 1924. The programme will be the same as that of last year. The number of students to be admitted to the course is limited.

Application should be made to Professor Vogt, Universitäts Augenklinik, Zürich.

October 7.-Midland Ophthalmological Society (Annual Meeting) at the Birmingham and Midland Eye Hospital. 